Article

\title{
Sustainable Development of an Individual as a Result of Mutual Enrichment of Professional and Personal Life
}

\author{
Katarzyna Mikołajczyk (D)
}

check for updates

Citation: Mikołajczyk, K. Sustainable Development of an Individual as a Result of Mutual Enrichment of Professional and Personal Life. Sustainability 2021, 13, 697. https:// doi.org/10.3390/su13020697

Received: 18 December 2020 Accepted: 12 January 2021 Published: 13 January 2021

Publisher's Note: MDPI stays neutral with regard to jurisdictional clai$\mathrm{ms}$ in published maps and institutional affiliations

Copyright: (C) 2021 by the author. Licensee MDPI, Basel, Switzerland. This article is an open access article distributed under the terms and conditions of the Creative Commons Attribution (CC BY) license (https:// creativecommons.org/licenses/by/ $4.0 /)$.
Institute of Human Capital, SGH Warsaw School of Economics, al. Niepodległości 162, 02554 Warsaw, Poland; katarzyna.mikolajczyk@sgh.waw.pl

\begin{abstract}
Presently, the development of civilization requires a vision of balancing the interests of employees and employers in the sphere of work as never before. Work-life balance is directly linked to social sustainability. The aim of this article is to analyze various dimensions of mutual enrichment of the professional and private life of an individual and to describe how positive experiences in professional and non-professional life influence the improvement of satisfaction, health, and achievements, thus enabling the sustainable development of the individual. The conducted research was of a qualitative nature. Thematic exploration was used to analyze the findings of 34 in-depth interviews with experienced HR managers and employees at various levels of enterprises in Poland. The research shows that the work and personal life of the respondents interact, complement, and enrich in different ways, depending on the stage of the employee's life. Habits developed by practicing a specific sport discipline or other type of hobby are helpful in the effective implementation of professional tasks. In addition, non-professional interests, including communing with culture and art, have a positive impact on professional activities. On the other hand, the respondents emphasized that thanks to their professional activities, specific to the type of work they perform, they are sometimes more extroverted, meticulous, organized, and consistent when performing activities outside of work and in other aspects of private life.
\end{abstract}

Keywords: work-life balance; work-life enrichment; outside-of-work activity; sustainable human capital development; COVID-19 pandemic

\section{Introduction}

Dynamically occurring changes, uncertainty, unpredictability, and ambiguity of events, as well as the intensified development of modern technologies shape today's reality. Current civilization's development requires, as never before, emphasis on the vision of balancing the interests of employees and employers in the sphere of work [1]. After all, work-life balance is directly related to social sustainability. Sustainable development of human capital is a complex concept that covers the areas of human activity on many levels of human life, both on a micro and macroeconomic scale [2]. In the literature on the subject, the factors of sustainable development are assigned to three areas: the natural environment, the economy, and society, where a good quality of life for present and future generations is an important goal. The implementation of the concept of a sustainable organization in the area of human capital management draws attention to the need to achieve not only the economic goals of the enterprise, but also meeting and balancing the needs of employees. Sustainable human resource management supports the organization's sustainable development strategy, emphasizes fair treatment, cares for the development, health, and well-being of employees, supports environmentally friendly organizational practices, assumes the development of employees' competences, and promotes work-life balance. Moreover, it relates to the social performance that contributes to the long-term development of the organization, that is, to a sustainable organization. At the same time, sustainable human capital management allows for the highest work efficiency, taking into account the well-being of 
not only employees but also other stakeholders of the organization. Maintaining a balance between work and life for employees not only improves the quality of personal life, but also creates a competitive edge for a company and promotes continuous growth. From this point of view, the subject of this study seems to be very important.

Striving for a work-life balance is related to many socio-economic issues, including productive use of labor resources and the ability to compete in the future by developing intangible assets, increasing fertility rates, gender equality, and improving quality of life. The lack of its optimal implementation causes far-reaching effects of a socio-economic nature. One of the results of the civilization changes involved a powerful compression of time, which characterized the life of modern man [3], resulting from the necessity to face an increasing number of challenges and the growing number of activities that fill time with limited resources [4], Especially if the changes taking place on the labor market in the sphere of its organization and forms of benefits [5] are also taken into account, including in particular, those taking place under the influence of the ongoing COVID-19 pandemic. These include more and more frequent interaction between work and private life and limiting them to the same space, a sense of the need to be available as a potentially working person at any time, and competition in the labor market. It is not surprising that more and more professionally active people struggle with the problem of balancing work and private life [6]. Working remotely, so common during the ongoing COVID-19 pandemic, may disrupt the natural context and force the combination of professional and social roles. Then-despite the flexibility offered by such a situation-there is a high risk of "stretching" working hours and disturbed rhythm of rest and regeneration of employees. There may also be difficulties in detaching yourself mentally from your leisure time work. Conducting the described research was to verify whether this is how employees perceive it and what actions can be undertaken by the companies to support their workers in sustainable development, including work-life enrichment, despite the current pandemic.

According to researchers, work-life balance should refer to the time balance, the balance of commitment, and the balance of an individual's satisfaction with his/her role at work and outside [7]. By understanding specific activities in both analyzed spheres, a man uses the same resources of his own time, energy, thoughts, and emotions, which are difficult to separate into two separate parts. At the same time, it should be emphasized that balance does not mean equal division of time between work and other activities, and the amount of time spent on specific activities and the frequency of their performance are not synonymous with the importance of this activity for a given person. It results, among others, from the subjectivism in the assessment of the relationship between work and private life, which is the result of the value system adopted by the individual, his personal characteristics, age, mood, family situation, the way of organization and type of work performed, as well as the complexity of the culture in which he functions [8]. A lot of research suggests that unwinding from the job during off-job time is important to avoid health-impairing effects [9-11]. The negative consequences of the imbalance between the analyzed areas of life do not only affect the individual. The temporary inability to meet specific groups of needs relating to personal, social, and leisure life, as well as the lack of satisfaction with them, will also affect the functioning of the individual at work, due to the interdependence and complementarity of individual spheres of human life and the compensatory nature of work-life relations [12].

This article is devoted to the analysis of solutions used in companies in Poland, aimed at maintaining work-life balance and supporting employees in their non-professional activities. The considerations undertaken by the author are part of the philosophy of balancing the needs of employees and promoting work-life balance, the key element of which is the postulate of a harmonious process of growth of all areas of human functioning and activity, as well as satisfying physical and mental needs guaranteeing a high quality of life without harm to society, the environment, and the economy. The main aim of the study is to analyze the mutual relations between work and non-professional activity in the context of the mutual enrichment of professional and personal life. From an organizational 
point of view, maintaining a balance between the above-mentioned areas of employee functioning allows for the full use of their potential [13]. The important goal of this study is to show that sustainable employee development does not have to involve the settlement of the dilemma of whether employees are more important than the financial success of an organization or environmental protection, but on the contrary, sustainable human capital management leads to simultaneous benefits in all areas. In this context, the question of activities supporting employees in maintaining this balance becomes extremely important, so that the applied solutions are beneficial both for employees and profitable for the companies employing them.

In recent years in Poland, there has been a growing cult of work with being busy accorded the greatest value. It is a determinant of status and prestige and is also a testament to the dedication of employees to the organizations employing them. Currently, one of the most important sources of maintaining the company's competitive advantage are its employees who, apart from their professional role, have equally important life roles or social functions. That is why business owners should be aware of human involvement in various areas of life and create favorable conditions for that participation.

The article is divided into three main parts. The first part describes the theoretical foundations of the analyses and their conceptual framework. The second part is devoted to the methodology of data research and analysis. The third part focuses on presenting and discussing the key results.

\section{Theoretical Background and Conceptual Frameworks}

\subsection{Work-Life Balance-The Evolution of the Idea from Work-Family Balance to Work-Life Balance}

The term work-life balance first appeared in the 1970s in the United States and initially referred to various family-related initiatives. This was linked to the crisis of the male breadwinner model as a result of the massive entry of women into the labor market. Starting from the 1990s, this term refers to initiatives aimed at providing support in the field of balancing professional and non-professional roles for all employees, regardless of their family situation [14]. We deal with work-life balance when work does not appropriate non-work life and when life outside of work does not come at its expense [15]. This state can be defined through the prism of results, and in this context, it means the possibility of achieving goals in various spheres of life and through the prism of role, when it is related to the conflict of roles of the individual at work and outside of it. It is also important to achieve satisfaction in all areas of life. Striving for a state of balance means reconciling work and family commitments, education, care for one's health, social and civic involvement, and more. The essence of work-life balance is defined in the literature as the subject of focusing attention on maintaining balance between work and private life, thus allowing the individual to strive for self-fulfillment in non-work aspects of life while maintaining understanding of the multidimensionality of the situation [16]. Balance between work and life outside of it refers to both the employer's and employee's attitudes that manifest themselves in efforts to achieve this balance. The starting point is the perception of the sphere of professional and personal life as complementary, not as opposites.

In the literature on the subject, the concept of work-life balance is defined quite differently. According to David Clutterbuck, it is a state in which an individual deals with a potential conflict between different requirements for his time and energy in such a way that his desire for prosperity and fulfilment is satisfied [15]. The determinant of achieving a work-life balance is based on the various requirements for investing a person's time and energy, the ability to make choices about investing time and energy, and to select the values on which these choices should be based, and to make them consciously. In theory, the workfamily conflict was first defined in the mid-1960s by a team of researchers who concluded that it occurs when work and family requirements are, to some extent, incompatible with each other [17]. Other researchers in the mid-1980s found that this conflict arises when role requirements related to one area of life make it difficult or impossible to fulfil role requirements related to another area of life [18]. Moreover, research has shown also that 
work-related ICT use outside work hours is generally related with more work-to-home conflict [19].

According to Patricia Voydanoff's concept [20,21], balance is closely related to the quality of an individual's professional and family roles and concerns the assessment of the extent to which labor resources help meet the needs of the family, and the positive impact of family resources on the implementation of tasks related to professional work.

On the other hand, according to another theory, work-life balance includes the following components: time balance, which means the same amount of time spent on work and family life, and commitment balance, which is associated with the same level of involvement in work and family life, and the balance of satisfaction, which concerns the same level of satisfaction with the individual's activity at work and in family life [7]. Such a concept of work-life balance, regarding the equal degree of involvement in various spheres, which may theoretically be considered contradictory, raises doubts. Currently, we should rather view work-life balance as a way of integrating various spheres of life into a harmonious and complementary whole and investigate the well-being implications of work-to-life boundary enactment [22]. After all, the proportions of an individual's involvement in particular spheres of life may change, depending on, for example, the stage of the life cycle. It should also be emphasized that the balance between work and non-professional activities varies from person to person, depending on age, sex, education, or life roles [23]. Therefore, there is no one universal construct of balance in terms of work and personal life.

The next stage in the development of the concept of work-life balance was the fact that experts noticed that the family is not the only sphere of an individual's functioning, which may affect one's well-being or fulfilment of professional duties. Social, civic, cultural, social, religious activities, sports, hobbies, leisure, education - these are only a few of the essential elements of human life that may be in balance or outside of their professional work [24]. It should be emphasized that the concept of work-life balance is based on finding an appropriate balance between work and private life, which means that it is not about maintaining the traditional model in which both spheres are treated separately [15]. The idea of balancing work and life is to help people realize themselves in each of these areas, giving them satisfaction, but also increasing their possibilities and potential. Therefore, work-personal life balance can be defined as the possibility of achieving goals in various spheres of life [25]. Employees are constantly trying to reconcile the requirements of professional work with personal life, the need to learn and develop their professional competencies throughout their lives with social obligations and the willingness to find time for recreation. Reconciling the requirements of work with the requirements of personal life may become possible, among others, thanks to the appropriate organization of time and support from relatives and colleagues. The concept of work-life balance understood in this way is quite broad. It concerns the balance between work and various areas of non-work life. Each working person has time at their disposal, which, in order to achieve full satisfaction in life, should be spent [15]:

- on yourself, to meet your own physical and emotional needs;

- on professional work, which is necessary to obtain funds to meet various needs (work is also a means of self-fulfillment);

- on family, as well as friends, other people with whom they have strong emotional connections; and

- $\quad$ on other people (e.g., through civic actions and for the broadly understood community).

As noted by Clutterbuck [15], the inability to meet the needs of employees who want to be fulfilled in life is the cause of most of a company's problems, including those related to achieving a competitive advantage and maintaining profitability. These include, among others: stress-related absenteeism from work, inability to retain talented employees in the company, insufficient initiative and creativity, a low level of customer service, unethical employee behavior, low commitment, and low motivation. Intentional and conscious building of appropriate working conditions leads, above all, to the proper development of employees and the implementation of the strategic goals of the organization in a sustainable manner. 
The results of research conducted in various countries around the world confirm the connection of companies' efforts to balance professional and personal life with economic benefits, such as reduced absenteeism and liquidity of staff, protection of investment in employees, lower costs of recruitment and training, sick leave, reduced employee stress level, greater employee loyalty, increased productivity, and improved company image [26]. It should also be added that an active approach to the issues of work-life balance usually does not directly affect productivity, competitiveness, final financial results, or profitability of capital; it only creates favorable conditions in which specific variables can support the basic factors determining the economic performance of the company [27-29]. The research shows that the condition of effectiveness and efficiency of work-life programs is their universality, which means that they should be addressed to all employees and be adjusted to the socio-demographic structure and formal organization [30,31].

\subsection{Work-Life Enrichment-Experiences from One Role Improve the Quality of Life in the Other}

The negative interaction between the considered roles of an individual has an already established terminological and conceptual position. On the other hand, the positive mutual influence between work and private life is still an area of research and discrepancies, including when it comes to definitions. In the literature on the subject, you can find terms such as positive radiation, facilitation, enhancement, enrichment, and penetration. These terms are often used interchangeably, but according to the researchers [32-35], each of the above terms emphasizes a different aspect of the positive impact of the multiplicity of roles. Empowerment is about acquiring resources and experiences that contribute greatly to coping with the hardships of everyday life. Positive radiation or penetration indicates the mood, values, behavior, and skills important for the transfer between work and life outside of it (or vice versa) to meet the needs of these spheres. Enrichment refers to individual assessment because fulfilling a given role can provide many valuable cognitive and emotional benefits to the second role [36]. On the other hand, facilitation means making it easier to meet the requirements in a specific area of functioning, thanks to participation in another area [37].

Already in the 1980s, it was noted that the interdependencies between non-work life and work did not boil down solely to the fact that they were or were not in conflict with each other. Taking into account the possible negative impact of these two areas, attention was also drawn to their mutual, positive relationship. Researchers of [38] found that the side effect-positive correlation between work and non-work-related activities-occurs more often than compensation-the negative correlation between work and non-workrelated activities. In this way, the concept of mutual enrichment of professional work and life outside of work was created-the so-called work-life enrichment. This enrichment can be understood as the degree to which experiences in one role improve the quality of life in the other [39]. Enriching life and work is a two-way process: work experience can have a positive impact on the quality of private life, and non-work experience can improve the quality of life in the professional sphere. For example, private life can become a source of positive emotions, which will be transferred to professional functioning [40]. Another form of enrichment is the situation when work shapes the skills, behavioral patterns, attitudes, or ways of thinking in an individual, which make it easier for him/her to fulfil, for example, family or civic roles. Employees may, as a result of their work, develop the habit of duty or gain self-confidence, and these features allow them to become a better partner, social activist, friend, or parent [41].

In the studies on the described issues, the analysis applied to which areas of nonprofessional functioning of individuals are most disturbed by the work performed [42]. It was found that three spheres of life of employees were in particularly strong conflict with their work: health, including physical exercise and doctor visits, family, and leisure (among others, hobbies, playing sports, reading books, watching TV, travelling). Interestingly, the results were similar for both married and single employees. These results can be used to argue the thesis that is becoming more and more popular; that work-life enrichment 
is not limited only to harmonious relations between work and family, but it is a certain state of synergy between professional functioning and the non-work life of an employee in general. Moreover, the latest research shows that work-to-family conflict negatively relates to family authenticity, and work-to-family enrichment positively relates to work and family authenticity [43].

However, what are the consequences of positive enrichment and the balance between roles? Researchers carried out a meta-analysis of studies devoted to the positive impact of professional and family roles, distinguishing three categories of consequences: workrelated, non-work-related, and health-related [44]. The first group of results concerns the positive effects of enrichment and balance on job satisfaction and emotional commitment to work. At the same time, the above variables are not directly related to the intention to leave the organization. While positive enrichment shapes the level of family satisfaction, it does not translate into the level of life satisfaction (the second group of effects). Outcomes in terms of physical and mental health are influenced by the positive enrichment of professional and personal life. The above-mentioned studies show that fulfilling one role improves functioning in the other role, and positive work-life synergy has a greater impact on work-related outcomes, while positive life-work synergy empowers on work-related outcomes.

Consequently, companies undertake various activities to improve positive empowerment and balance between personal and work life. These are activities both at the employee level (e.g., creating attractive working conditions) and the organizational level (e.g., introducing specific solutions in terms of working time and its control) as well as at the level of the entire society (e.g., providing assistance with dependent care of children or family members). One of the practical ways to achieve work-life balance is to accept that these two spheres are extremely important to a person, and that many values and other resources can permeate from one area to another. However, you should be aware that the work-personal life relationships are so complex that it is not always possible to achieve these goals.

\section{Materials and Methods}

The described research is explanatory and qualitative. In the context of the abovementioned theoretical premises, it seemed important research to recognize, identify, and evaluate selected human capital management practices conducive to the sustainable development of an individual. The results presented below are an attempt to fill this research gap. They are part of a larger research project entitled "Human capital management in the conditions of sustainable development", conducted at the Institute of Human Capital of the Warsaw School of Economics.

\subsection{Characteristics of the Research Group}

The research group covered 34 people, including 18 people employed in managerial positions in the HR area and 16 employees employed in various positions in organizations in Poland (including 11 people in managerial positions). Most of the respondents were women employed at large companies in the service industry. The profile of the respondents is presented in Table 1. Invitations to take part in the survey were addressed to representatives of specific global companies. The purposeful selection of the respondents was made to ensure reaching people working in large international organizations, employing 250 or more employees, based on the assumption that it is the largest organizations which are actively involved in activities aimed at maintaining work-life balance [45] and it will be likely to encounter the best or inspiring practices in this area within selected organizations. The intentional participation of these two groups of respondents was dictated by the desire to obtain opinions from two perspectives-people responsible for the personnel policy of the organization, and on the other hand, the beneficiaries of HRM practices. The respondents had extensive professional experience and their length of service in a given position ranged from 5 to 23 years. It seemed to be the best choice for the identification and selection of information-rich cases related to the phenomenon of interest. 
Table 1. Profile of interview participants.

\begin{tabular}{|c|c|c|c|c|c|c|}
\hline \multicolumn{2}{|c|}{ Position } & \multicolumn{2}{|c|}{ Gender } & \multicolumn{3}{|c|}{ Size of Entity } \\
\hline Managerial & Non-Managerial & Woman & Man & Large Company & Medium Company & Small Company \\
\hline 27 & 7 & 25 & 9 & 28 & 3 & 3 \\
\hline \multicolumn{7}{|c|}{ Industry } \\
\hline Trade & Media & Production & Public Sector & Services & \multicolumn{2}{|c|}{ Technology } \\
\hline 1 & 1 & 5 & 5 & 17 & \multicolumn{2}{|c|}{5} \\
\hline
\end{tabular}

\subsection{Methodology for the Survey and Analysis}

A structured individual in-depth interview (IDI) was used as the research method [46]. The textual data analysis was derived from the transcripts of interviews, which were categorized and coded. In-depth individual interviews made it possible to identify actions taken by companies and employees' expectations in selected areas of human capital management. The focus was on the following topics: 1) HR experts gave their comments on work-life balance, 2) employees commented on the role balance, extra-professional activities, and development. The current situation of the COVID-19 pandemic crisis was taken into account as background to the discussed issues. The interviews were conducted from June to August 2020. As a result of IDI implementation, material of 338 pages was obtained (34 interviews were conducted, total duration-1771 minutes). The interviews were recorded, and then transcripts were prepared in the form of text documents. The detailed steps for the study procedure are presented in Figure 1.

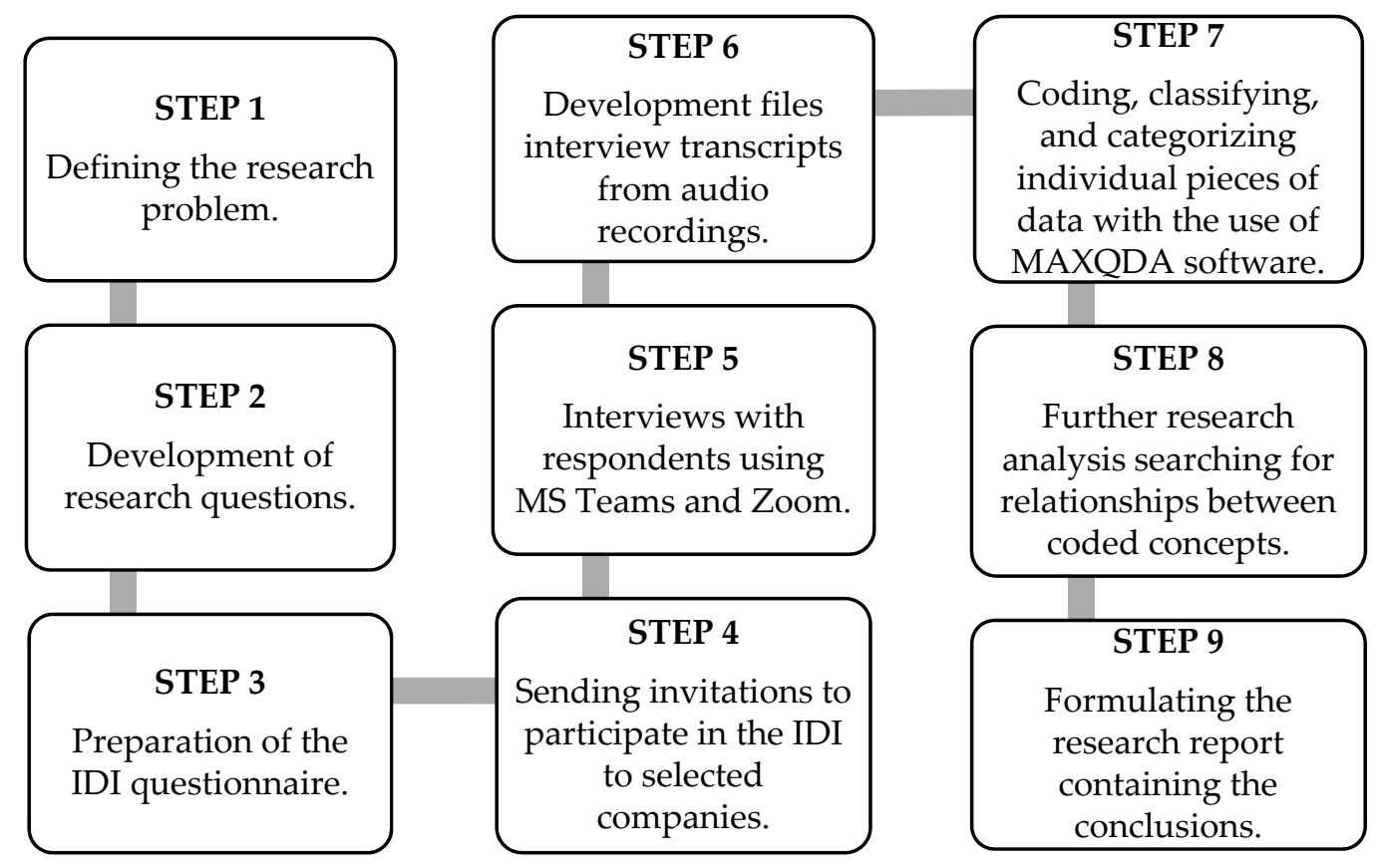

Figure 1. The detailed steps for the study procedure.

The key analytical process in qualitative research in social sciences is coding-classifying and categorizing individual pieces of data, combined with a system of finding them. The content of interviews was catalogued by topic. The concept was also in this case the main principle of encoding qualitative data. Coding and searching for relationships between concepts was a key element in the process of research analysis [47]. During the analysis, open coding [48] was used to name and categorize phenomena by carefully examining the collected data. In this approach, the codes somehow impose themselves on the researcher as a result of analyzing and checking data. 
This article discusses the results of research on solutions used in Polish companies in the field of work-life balance and the factors determining their durability. The focus was also on the analysis of the forms of non-professional activities of employees, areas disturbed by their professional work, as well as the forms of support they expect and the manifestations of mutual strengthening of professional work and personal life of respondents. The impact of COVID-19 pandemic on these areas was also taken into account. In-depth interviews allowed the participants to share in-depth insights on work-life balance and non-work activity in the context of work-life enrichment. In the area of work-life balance, the following research questions were formulated, and addressed to HR experts:

- What solutions for maintaining work-life balance are used in companies?

- What factors (organizational and individual benefits) determine the durability of solutions in the field of work-life balance?

In the area of non-professional activity in the context of work-life enrichment, the following research questions were formulated, addressed to employees of various companies:

- What forms of non-professional activity do the respondents pursue?

- Which areas of non-professional functioning are most disturbed by their professional work? Has it changed during the pandemic and how?

- What forms of support and solutions do employees expect from the employer to be able to fulfil themselves in their personal lives and develop professionally?

- What activities outside of work strengthen employees in their work and vice versa, what activities at work have a positive impact on their personal life?

\section{Results}

The results of the study were divided into three parts. The first covers aspects related to work-life balance from the perspective of HR managers and considering the expectations of employees in this regard. The second part focuses on the analysis of the forms of nonprofessional activity undertaken by employees, the areas disturbed, and changes caused by the COVID-19 pandemic in this respect. The third part describes examples of mutual strengthening of the work and personal life of the respondents.

\subsection{Work-Life Balance-What Companies Offer and What Employees Expect}

The conducted research clearly indicates that companies in Poland use various types of organizational solutions to support employees in maintaining work-life balance. Detailed options are presented in Figure 2. The following were mentioned most frequently: flexible and compressed working hours; the possibility of remote work, 1-2 days a week; various forms of support for families (programs such as "2 hours for the family", parental leaves, subsidies for childcare, nanny in the workplace, workshops on improving parental competency, organization of family corporate events); various types of workshop activities and events that help employees to take better care of themselves, their physical and mental condition and the balance between various spheres of life; the availability of psychological consultations; additional days off (on the occasion of birthdays); personal concierge services fulfilling private requests of employees; or financing a family childbirth. Moreover, most of the respondents emphasized that work-life balance in organizations is rather an element of organizational culture and best practices, rather than just strictly defined programs. Most companies promote respect for the employee's time, but at the same time, try to build a work culture based on the efficient performance of tasks. 
"We provide employees with flexible working hours, there are people working at non-standard hours, because they report such a need due to family obligations. Also, such an individualized approach is also possible." (R9)

"We organize various types of events and development activities for employees, related to promoting a healthy lifestyle, promoting such elements that are very important for our company and our group, i.e., broadly understood inclusion and diversity." (R12)

"We have a manager's competency model, in which we place great emphasis on the manager providing his people with support and balance in professional and private life. In this organizational culture, it is not welcome to exert a lot of pressure, overtime, things like that. Of course, it happens, because we are not able to get away from it, but these are not directions that are supported, it is not well perceived in our organizational culture, because the manager is supposed to manage the team so that his people have comfort work and time for their work and private life. And it is written in our competency model." (R17)

"Flexible working time for sure, also the possibility of remote work. If I do not have any meetings or recordings on a given day, then I can sit at home and actually work from home. This way, saving time for commuting. Simply respecting work-life balance, i.e., trying not to call me after 5:00 pm or when I have my vacation entered into the calendar or I am not there." (R12)

"Yes, I think flexibility is a good word, because it's not about imposing on anyone, for example, 4 days of remote work, one day of stationary work. Because everyone may have a different need. But this flexibility and understanding of different needs is quite important and I would like to see it strengthened both on the side of HR and management. Because I think that giving freedom when it comes to the style of work, the type of work, brings more results than simply putting everyone in one model." (R15)

"It's about building an organizational structure around these solutions. Being aware that it is ok, that it has its value, that it is important to us. And I also understand that not all people and not all employees may have the same approach, but the point is to build this awareness and make it consistent within the organization. So, it seems to me that this is the most important element for WLB to be sustainable." (R12)

Figure 2. Examples of verbatim reports about work-life balance employer's offer and employee expectations.

The expected forms of support from the employer, most frequently indicated by the respondents, which enable employees to fulfil both their personal and professional lives, largely coincide with what employers actually offer. Employees expect flexibility in the time and form of work and an increase in the pool of days off, respect for the employee's free time by the employer, and benefits supporting physical activity, learning foreign languages, or participation in culture. Interesting forms of development offered by the employer are popular (training, mentoring, coaching), lack of pressure from superiors, trust in the employee, and giving him/her freedom so that he/she can be accountable for the effects of his/her own actions, opposed to the time allocated for one's performance. As factors determining the durability of the solutions in the field of work-life balance, the respondents most often indicated building an organizational culture around these solutions, widespread use by employees, linking them with the strategy and mission of the organization and making them as flexible as possible for all employees.

Research shows that employers also support the development of passion and other non-professional activities of their employees. Companies finance or co-finance employees participation in sports activities, organize sports games, and invest in their own sports team. They enable the development of employees' interests through activities in the form of volunteering, setting up interest clubs, co-financing participation in culture, publishing articles on the interests of colleagues in internal magazines and platforms, or implementing mentoring projects. They also initiate a number of activities to support employees in fulfilling various life roles. 


\subsection{The Areas of Non-Professional Functioning of Employees and Changes in this Regard Resulting from the COVID-19 Pandemic}

The research shows that employees need time to develop their passions and private life, and employers more and more often support the development of the non-professional activities of employees. Detailed information are presented in Figure 3. Supporting the achievement of employees' professional goals through the development of their competencies is one thing-but providing them with a place to develop creativity and maintain a balance between professional and personal life is also, according to employees, a sign of a modern employer. Forms of non-work activities most often indicated by the respondents were mainly activities resulting from fulfilling various life roles (mother/father, marriage/partner roles), as well as sports, tourism, gardening, cooking, participation in culture, playing musical instruments, reading books, and the development of specific cognitive interests.

The respondents most often indicated family life and physical activity as the areas of non-professional functioning most disturbed by professional work. They talked about the problems associated with changing the organization of work, which to a large extent took a remote form. On the one hand, remote work creates new opportunities; on the other, it enters the area of private life and is also a source of deprivation of the social needs of employees. The respondents emphasized that due to the COVID-19 pandemic and the need to work remotely, their life roles somehow "merged" with professional roles, working hours were extended and they experienced difficulties in completing their professional duties. Research indicates the importance of work segmentation for maintaining a sense of well-being and balancing the sphere of private life and professional activity. Greater integration of these two areas is visible in managers whose work boundaries are stretched, and work-life balance is clearly disturbed. The pandemic made it difficult for employees to take up physical activity due to the closure of gyms and the need to maintain social distancing and made travelling difficult. In response to these restrictions, some employees switched to other forms of physical activity-jogging, gymnastic exercises at home, cycling trips, and walking in the woods. On the one hand, the conducted research revealed people who complained about the lack of time to develop their interests, and on the other hand, those who had just developed new interests during the pandemic.

\subsection{Work-Life Enrichment-Mutual Positive Work-Life Relationships Perceived by Employees}

The conducted analyses show that the work and personal life of the respondents interpenetrate, complement, enrich, and compose in different ways, depending on the stage of the employee's life. The respondents indicated activities outside of work that strengthen them in their work and vice versa-activities carried out as part of their professional work have a positive impact on their personal life. In a broader context, the respondents statements may also lead to greater awareness that we all have different priorities and that there should be more than one path in life and career success. Detailed information are presented in Figure 4.

The respondents' statements indicate that habits developed by practicing a specific sport-related discipline or other type of hobby are helpful in the effective implementation of professional tasks. Furthermore, interests outside of work, such as an interest in culture and art, have a positive impact on their professional activities, broadening their horizons and opening them up to other points of view. The family was also often indicated by the respondents as a factor strengthening their ability in effective time management and efficient performance of employee duties. On the other hand, the respondents emphasized that, thanks to their professional activities, resulting from the specificity of the work they perform, they are sometimes more extroverted, meticulous, organized, and consistent in non-professional activities and in private life. Some of the respondents emphasized that their life roles (parent or wife/husband) motivates them to introduce a greater balance into their professional and non-professional functioning and enable them to discover new passions. 
"I have a lot of passions and hobbies. I try to distinguish those elements that are important to me and deal with them. I am a bibliophile, I think I bought 500 books recently and I haven't had time to read them yet, but before that I had a little more time, so my annual target was always reading 100 books. For today it is unfortunately unreal." (R5)

"Raising my daughter is a big role now, and the hobby is sport: swimming, cycling. I am also a player, i.e., TV games are a hobby that has been with me for years." (R11)

"I spend a lot of non-work time with my family, we usually fill this time with outdoor activities, cycling. What has changed in the last year is that we have fewer opportunities to go somewhere abroad. So, we started looking for a local replacement. My hobby is playing the piano, it relaxes me and distracts me from current topics." (R15)

"This moment of the lockdown was a very cool moment to slow down for a moment and do nothing, simply. And turn to the things that you always wanted, are within reach, but so far have been carried out randomly or waited their turn. I am thinking of making up for the shortcomings of the series, finally finishing a book I started half a year ago and dusting somewhere on the bedside table. In the beginning, it was like this. After a few weeks, when the locking element began to improve, the need for some movement came to the fore. So, going for a walk, preparing the bike for the season, many people from my team saved themselves by running and thus maintaining this balance of body and soul." (R3)

"I spend a large part of the day at home, which I am not happy with, as I preferred to spend most of the day outside. Go to various restaurants or cafés, just meet friends somewhere, and eat something and have a good time. However, throughout this situation, I was able to look for new passions and spend time with my family, which is very important nowadays and we often forget about it." (R8)

"I will refer to the fact that working in this large corporation, I had very little free time. And I gave up my passions and because of lack of time and lack of strength. I think that my relations with people suffered a lot. Very often I did not have time to meet with friends. And it seems to me that this rush and this job meant that if I had to say what was the most important thing I lost, it would probably be the time I could devote to be a mother, a wife." (R13)

"It's like that because of COVID I work between making dinner and playing with the child. And when the child is preoccupied with himself, I am actually trying to do something for work. It is very difficult. Also for me, a great psychological burden associated with it. All my non-professional aspects are very disturbed." (R12)

"Everything has changed! For example, the inability to leave the house or go for a walk with the child, in this hottest period of the lockdown. Seriously. Now I have no opportunity to go for a walk with the child because I have to work. So, my child very often sits at home all day, because I do not have an hour or two to go for a walk with my child. What has changed? There is also no travelling, no physical activity like fitness classes, I am afraid of going to the gym because of COVID-19. All my non-professional aspects are highly disturbed. My extra-professional functioning. It's nice that I can meet my friends on weekends to a very limited extent, I am also very happy that I can meet with my family now, because there was a time when we haven't met for a month or two. It was also very difficult." (R11)

"Unfortunately, during the pandemic, all sporting events were cancelled. This did not mean the end of practicing my passion, because more free time meant that I had time to run, to think about certain things, reevaluate my life and find new passions. Lately, I've been reading a lot of fantasy literature, which I love so much and read a lot of books during the quarantine period. Also, I spend a lot of time with my girlfriend. We both have more time to cook together, watch movies and TV series." (R8)

"I had to change the type of physical activity, because I was not able to go to the gym, so I started running a little, exercising at home a bit, but here it is very difficult for me to be regular. When I had a schedule written outside, I knew that if I did not leave at this point, I would not leave at all. And when it is up to me, sometimes I lack.... not even determination, but such consistency. It always seems to me that when I finish my work, then I will take care of it. So, I put work first, kind of." (R10)

Figure 3. Examples of verbatim reports about areas of out of work activities of employees and changes resulting from the COVID-19 pandemic. 
"Such a stillness at work, I must say, also leads to stagnation in life outside work. Maybe it has such an impact that because there are weeks when I really have nothing to do at work and I am bored and browse the Internet, I transfer this apathy returning home. I mean, I can sit down and spend the evening doing nothing. Starting at some stupid programs on TV. However, the previous president, who was much more demanding and indeed there was much more to this job and such mental involvement - oh, that's what I miss now - when you came back home, you really had some ideas, strength and wanted to do something more." (R2)

"It seems to me that by playing strategy games as a hobby since my teens, I was able to develop this ability to be strategically approached at work." (R11)

"I have the impression that the energy drawn in the personal area, dealing with things that fascinate us, affects the professional area. Not only energy, but also this experience. So, by doing some things completely unrelated to work, but which teach and develop something, you can then bring some new energy, experiences into what is happening at work. And many such things happened to me, because a lot of things that I learned at noncompany meetings, e.g., at product meet-ups or meetings of people who have been working remotely for years in other companies, are these experiences... I treat it, that it was from the professional field, but still performed as a personal activity. Well, because it was something that interests me and I treated it as my passion, hobby, I wanted to broaden my knowledge in this field. And then I was able to transfer it to the professional sphere, implement it in the company, and thanks to this, the results are better for our everyday work." (R15)

"I think that in my private life I am very orderly, specific, and well organized. It translated into how I function in my organization and how I arranged my work and cooperation with other people. It certainly translated more from my private life to my professional life. What I could say, what has translated from my professional life into my private life, is that I have a high self-esteem because what I do is fun and makes sense. I can see the sense in my work, and I can see the final effect with which I can be satisfied." (R12)

"I live my professional life so much that the boundary between personal and professional life has become very blurred. It is actually one and the same thing. I used to be a shy person and I have the impression that entering this path of professional development allowed me to spread my wings a lot. And if I had done it earlier, I would probably be in a different place today, but there is no regret. Better late than never. I think being a parent helps me a lot at work. So, I have the impression that there is a strong synergy here, the children are great, and they support me in that." (R10)

"There is no work and there is no life. There is either a life at work or work in life. And I think this is a direction that is also more and more often... I don't know if it has started to appear somewhere, that we should forget about the term work-life balance, because it makes no sense at all, only about quality life, or about other terms saying that the offline and online world has also ceased to have clear boundaries and we live in both at once, so we live in private life and at work at once. And this is the future we must learn." (R3)

"What I certainly take from my professional work, and which is useful in my personal life, is the ability to deal with difficult, stressful, low-key, and generally uncomfortable situations. I appreciate punctuality, the ability to act under time pressure, also soft skills, i.e., character traits that I have acquired over many years of my work experience and I use it most in my personal life." (R8)

"I believe that there is no good, effective manager who does not have his passions. If we do not get out of our bubble, we are only at work, we control everything, we are so closed, so mentally constrained that it cannot be done. However, I often tell my employees that I was here, I read it and I see that they open their eyes and some people say in a week "You know what, I was there too. And you were right, thank you for the recommendation". Well, I like to share knowledge, not only the professional one, but also the knowledge about the world. And I think that's why it doesn't tire me so much. Because everything seems to fit together. It permeates." (R9)

"Certainly, contact with people, I learned a lot in my work, not only business contact, but also social contact and social responsibility, because my company invests a lot in CSR. And it opened my eyes that it is also important and because of small things, you can do something great. And when it comes to contacts, through meetings, negotiating various contracts - not only in Polish, but also talking to the headquarters, with foreign partners, it also translated into a private part of my life." (R11)

"Certainly, various aspects are here, I have been training sports regularly for 10 years, so it has developed the habit of regularity. In general, I am an organized person in my private and professional life as well. On the other hand, what could have influenced me professionally was the fact that I am generally introverted and do not have much ease with interacting with other people. And in my current role I have to work with clients, so relationships are very important. It was some area that I had relatively underdeveloped and I had to work on it. This could affect my functioning outside of work. I just had to develop it." (R14)

Figure 4. Cont. 


\begin{abstract}
"At the beginning, I mentioned that you mix your personal life with professional life a bit and that it is sometimes difficult to distinguish between professional and personal activity. It is quite fluid. And here it is similar, there are in fact strictly professional things that affect my personal activity. This changes with the role. I observe it at home that along with learning new things, then I transferred them to my personal area, giving a specific example: when a few years ago we decided to further develop our area as part of an agile approach, i.e., less project approach, and more product one, more experiments, shorter iterations of work and faster drawing conclusions, less assumptions, more verification, then I started to take advantage of it in my personal life that much more often now I verify different things instead of going blindly into one thing that I assumed for myself that it is definitely correct. So, I try to check more things and it probably gives me a better effect at the end." (R15)

"I don't think I will be original here, but my family strengthens me for sure. We have such a tradition that we meet every Saturday for dinner at my mother's. These are the moments when I can ask my closest family for advice, opinion, even professional issues-I often use their advice at work. It also seems to me that playing the piano has made something in my life that has a spiritual and non-material dimension. It takes me to another world and this world is mine. It has always been there, when I was still studying at various music schools, it was very important to me and unfortunately, working 16 years in a corporation, I lost it. And now I am starting to remember it and it gives me a lot of strength and energy." (R13)

"I think having kids definitely makes us develop our more multitasking skill where we have a lot of different things and how to manage it all. At this point, it definitely appears when we have kids. In my case, children are a very good mobilization to really care for this balance and have time for home. Because I still remember myself as a young person, somewhere at the beginning of my professional career, when I did not have children, I used to spend a lot of time at work." (R16)
\end{abstract}

Figure 4. Examples of verbatim reports about work-life enrichment in the opinion of employees.

The results of the study show that it is worth treating professional and private life as allies, emphasizing their harmony and complementarity, opposed to the equal and proportionate division of time between these two spheres. Playing many different roles, e.g., a parent, partner, or employee, can, in fact, have a positive effect on the psychological condition of the employee-especially when all these roles are played very carefully and are managed as a whole. When faced with these types of choices, it is important to adopt a holistic attitude and treat a career as an integral part of life, not a separate, compulsory occupation. To avoid the penetration of toxic emotions in the work-life relationship (and vice versa), we should put everything in one "container" and organize it well—such a procedure can reduce the unnecessary tension between the two spheres.

Some of the respondents emphasized that the best ideas came about thanks to the fact that they talked with their children about professional matters at home. Even when work was very demanding, the most practical and effective roadmap, according to respondents, is to combine personal priorities related to work, family, health, and well-being into one system. Such a change of approach may result in an increase in the level of psychophysical energy, a more sober view of work, or an increase in the level of concentration on current tasks. According to the respondents, it is worth doing something so that work is not completely absorbing. Take care of your body and mind by making time for family life and other activities that recharge your batteries-all these activities ultimately increase your productivity as an employee. Employees should also remember what they are aiming for in their work, along with its deeper meaning.

\title{
5. Discussion and Conclusions
}

The findings show that the conscious role of the work environment in balancing the professional and non-professional activity of employees certainly fits in with the idea of sustainable development and the concept of corporate social responsibility, which can be applied not only to nature, economy, and society, but also to the life balance of an individual. In order to function effectively in both private and professional life, it is essential to maintain a balance between energy expenditure and its recovery. A healthy enterprise, operating in accordance with the concept of sustainable human capital development, is one in which an employee can count on understanding his/her needs, enabling the implementation of 
non-professional activities, in which stress is eliminated and healthy behavior is promotedincluding maintaining a work-life balance.

\subsection{Theoretical Implications}

Activities in the field of sustainable development of an individual should create system solutions leading to the achievement of economic and social goals. The imbalance between the different areas leads to significant losses. Empowerment activities are those with positive impact that help build a stronger, more sustainable society. Proper use of work-life enrichment is possible only after taking into account the specificity of the organization and its teams, and even individual employees, while maintaining high flexibility and creativity. Combining professional and non-professional interests allows for better use of the individual's potential and gives the opportunity to acquire a broader spectrum of competencies and new experiences [49]. People who draw inspiration, ideas, and trends from a variety of sources can often offer their employers a fresh perspective and out-ofthe-box ideas that go beyond solutions in one field. Balance is crucial for achieving not only life goals, but also professional goals, because the employee often introduces the same positive or negative attitudes into the workplace that he/she cultivates in non-professional activities.

Enabling the employee to fulfil his/her job outside of work may also contribute to one's general intellectual development, significantly improving well-being [50], and thus increasing energy and optimism about the performance of his/her professional duties. As a consequence, a happy employee functions better at work, is more creative and focused, and cooperates better in a team [51]. It is also easier for the employee to strive for an integrated self, building a coherent image, both in professional life and outside of it. Employee's positive emotionality is also associated with a lower tendency to engage in behaviors that are unfavorable to health, along with fewer hospitalizations and absences from work. In order to feel well, the employee needs emotional diversity-an authentic, complex, and rich life. Certainly, an employee who has time for private life and pursues his/her passions is more effective in everyday professional tasks [52].

The most important conclusions and usefulness of the presented reflection are related to the thesis that the sustainable development of human capital cannot be analyzed without taking into account the non-professional sphere, which is an important element in the life of an individual. Only under conditions enabling complementarity of the indicated areas will it be possible to improve the individual, both in general and professional terms, to the benefit of both the employee and the employer. A complete analysis of the mutual relations between work and private life cannot ignore the issue of mutual enrichment of professional and personal life.

\subsection{Managerial Implications}

The concept of sustainable human capital management, including care for work lifeenrichment, provides many benefits to companies, their employees and their relatives, as well as the environment. Currently, businesses need the creativity and innovation of employees, among other things, in order to be able to stand out and compete in this modern, uncertain, dynamic, and constantly changing business environment. When employed people do not have the time to develop in their personal lives, companies can end up losing a lot. The possibility of other fulfilment, outside of work, may contribute to the fact that employees will fulfil their professional duties much better, for example, by developing, thanks to their passions, some key skills necessary for effective functioning in the work environment [53]. A creative hobby allows you to open your mind to many different perspectives, which can be a very useful feature in your professional life. The research results clearly indicate that creative non-professional activity may constitute a recreational activity, which provides employees with the necessary resources for professional work at a high level [54]. Organizations that provide the most talented people with personalized 
development plans and opportunities to pursue non-professional interests, as well as build a supportive and inclusive culture, benefit more from those employees' creativity.

From the statements of the respondents, it can be concluded that while maintaining considerable flexibility in taking specific actions and decisions, it is the foundations, in the form of defining the way of understanding work-life enrichment, that constitute an element that stabilizes and indicates specific, clear directions for employees, which turns out to be extremely valuable, including in emergencies such as the global COVID-19 pandemic.

The ongoing pandemic accelerated efforts to improve communication with employees, including obtaining their opinions on various topics. If employers listen to the needs of their employees, it may be easier for them to create space for work-life enrichment. In this new reality, an agile approach to employee development can work much better. The activities of managers should also take into greater account the changing and unpredictable reality as well as the evolving nature of information and communication technologies (ICT). The COVID-19 pandemic may contribute to the analysis and modernization of existing offerings for development in organizations and foster a culture of lifelong learning. It has become necessary to move the area of development from physical training spaces and face-to-face contact to the internet environment. There are many reasons to believe that the situation in which a large part of business interactions has moved to different forms of remote communication will last longer and become our new, everyday life. Therefore, it is worth considering how to effectively implement development processes under such conditions in order to gain sustainability. As results from the conducted research, it may be helpful in this respect to focus on a bilateral (employee-employer) search for development areas and tools and adjust the course of career paths to the roles performed in non-professional life. In the face of a pandemic threat, managers take into account the need to ensure safe and hygienic working conditions for all employees, variable availability of individual resources and employee competences, and provide additional online training for voluntary implementation by employees. Training offers related to emotions and stress management, attentiveness training, empathic communication, and work-life balance were most frequently selected by the employees. The managerial attitude can also help workers to develop their potential during the pandemic. Shortening the time for online meeting and not organizing them at the end of the workday, and focusing on the assessment of the achieved results, and not control and verification of the time spent on professional activities by an employee, can certainly support work-life balance.

\subsection{Limitations and Directions for Future Research}

Although this research makes important theoretical and empirical contributions (mentioned above) to the existing literature, some limitations must be kept in mind when drawing conclusions from the reported results. The main empirical contribution of this article is drawing attention to factors beyond the sphere of work that may affect the employee's commitment to work and enable the realization of his/her potential. It is worth emphasizing that although the respondents in these in-depth interviews were limited to employees from Poland, the vast majority of their places of employment are Polish branches of international corporations. Therefore, it can be concluded that the described research results may also be of importance in the international discourse. Some limitation may be the intentional selection of the research sample, which preclude the generalization of the obtained results. Another limitation of the presented proposal is the reference of sustainable development of an individual to the general definitions adopted in this study. It should be emphasized that there may be significant differences between individual cultural conditions in which employees function, affecting their perception of what work-life enrichment really is.

In addition, the fact that IDIs were conducted during the COVID-19 pandemic probably influenced their final tone. The crisis caused by the COVID-19 pandemic has consequences on many levels-in the health sector, the economy, the labor market, education, perception of technological advances, or the approach to new, related, legal regulations. It 
turns out that new technology is crucial in the fight against the crisis, because it enables communication and remote work or online learning on an unprecedented scale. To some extent, the crisis has also forced us to face a number of outstanding issues related to the scale of technological interference in both professional and private life.

Certainly, this issue requires further research, especially with regard to the increasingly common model of hybrid work and the accompanying challenges in terms of searching for effective solutions that can be applied in a situation of performing professional duties, more and more often in a private space. Quantitative research may be the next research step that allows to deepen the obtained results. The quantitative analysis could help to reliably estimate how much employees' work-life balance has become disturb during the pandemic and if employees can see the possibility for implementation of work-life enrichment during the hybrid or remote work.

The pandemic continues; no one can predict how long for and how it will change the working conditions and functioning of companies and employees. Instead of focusing only on survival, it is worth trying to use this reality for smart solutions that can be introduced into the organization to support employees in permanent sustainable development, taking into account both their professional activity and personal life.

Funding: This research received no external funding.

Institutional Review Board Statement: Not applicable.

Informed Consent Statement: Not applicable.

Data Availability Statement: The data presented in this study are available on request from the corresponding author.

Conflicts of Interest: The author declares no conflict of interest.

\section{References}

1. Katić, I.; Knežević, T.; Berber, N.; Ivanisevic, A.; Leber, M. The impact of stress on life, working, and management styles: How to make an organization healthier? Sustainability 2019, 11, 4026. [CrossRef]

2. Ferreira, P.; Gabriel, C.; Faria, S.; Rodrigues, P.; Sousa Pereira, M. What if employees brought their life to work? The relation of life satisfaction and work engagement. Sustainability 2020, 12, 2743. [CrossRef]

3. Gleick, J. Faster: The Acceleration of Just About Everything; Vintage Books: New York, NY, USA, 2000; ISBN-10: 9780679775485.

4. Rose, J. Never enough hours in the day: Employed mothers' perceptions of time pressure. Aust. J. Soc. Issues 2017, 52, 116-130. [CrossRef]

5. Troup, C.; Rose, J. Working from home: Do formal or informal telework arrangements provide better work-family outcomes? Community Work Fam. 2012, 15, 471-486. [CrossRef]

6. OECD. Better Life Index. Available online: http:/ / www.oecdbetterlifeindex.org/countries/poland/ (accessed on 23 November 2020).

7. Greenhaus, J.H.; Collins, K.M.; Show, J.D. The relation between work-family balance and quality of life. J. Vocat. Behav. 2003, 63, 510-531. [CrossRef]

8. Greenhaus, J.H.; Parasuraman, S.; Collins, K.M. Career involvement and family involvement as moderators of relationship between work-family conflict and withdrawal from profession. J. Occup. Health Psychol. 2001, 6, 91-100. [CrossRef]

9. Bennett, A.A.; Bakker, A.B.; Field, J.G. Recovery from work-related effort: A meta-analysis. J. Organ. Behav. 2018, 39, 262-275. [CrossRef]

10. Firoozabadi, A.; Uitdewilligen, S.; Zijlstra, F.R.H. Should you switch off or stay engaged? The consequences of thinking about work on the trajectory of psychological well-being over time. J. Occup. Health. Psychol. 2018, 23, 278-288. [CrossRef]

11. Kleine, A.K.; Rudolph, C.W.; Zacher, H. Thriving at Work: A Meta-Analysis. J. Organ. Behav. 2019, 40, 973-999. [CrossRef]

12. Chan, X.W.; Kalliath, T.; Brough, P.; Oi-Ling, S.; O'Driscoll, M.P.; Timms, C. Work-family enrichment and satisfaction: The mediating role of self-efficacy and work-life balance. Int. J. Hum. Resour. Manag. 2016, 27, 1755-1776. [CrossRef]

13. Pedersen, V.B.; Jeppesen, H.J. Contagious flexibility? A study on whether schedule flexibility facilitates work-life enrichment. Scand. J. Psychol. 2012, 53, 347-359. [CrossRef] [PubMed]

14. Harris, L.A.; Foster, B. The Drivers of Work-Life Balance: A Critical Review. In Proceedings of the 22nd Conference of the Association of Industrial Relations Academics of Australia and New Zealand, Melbourne, Australia, 6-8 February 2008.

15. Clutterbuck, D. Managing Work-Life Balance; Chartered Institute of Personnel \& Development: Wimbledon, UK, 2003 ; pp. 16-91.

16. Kalliath, T.; Brough, P. Work-life balance: A review of the meaning of the balance construct. J. Manag. Organ. 2008, 14, 323-327. [CrossRef] 
17. Kahn, R.L.; Wolfe, D.M.; Quinn, R.; Snoek, J.D.; Rosenthal, R.A. Organizational Stress: Studies in Role Conflict and Ambiguity; John Wiley \& Sons: New York, NY, USA, 1964.

18. Greenhaus, J.; Beutell, N. Sources of conflict between work and family roles. Acad. Manag. Rev. 1985, 10, 76-88. [CrossRef]

19. Gadeyne, N.; Verbruggen, M.; Delanoeije, J.; De Cooman, R. All wired, all tired? Work-related ICT-use outside work hours and work-to-home conflict: The role of integration preference, integration norms and work demands. J. Vocat. Behav. 2018, 107, 86-99. [CrossRef]

20. Voydanoff, P. Toward a conceptualization of perceived work-family fit and balance: A demands and resources approach. J. Marriage Fam. 2005, 67, 822-836. [CrossRef]

21. Voydanoff, P. The effects of work demands and resources on work-to-family conflict and facilitation. J. Marriage Fam. 2004, 66, 398-412. [CrossRef]

22. Wepfer, A.G.; Allen, T.D.; Brauchli, R.; Jenny, G.J.; Bauer, G.F. Work-life boundaries and well-being: Does work-to-life integration impair well-being through lack of recovery? J. Bus. Psychol. 2018, 33, 727-740. [CrossRef]

23. Emslie, C.; Hunt, K. 'Live to work' or 'Work to live'? A qualitative study of gender and work-life balance among men and women in mid-life. Gend. Work Organ. 2009, 16, 151-172. [CrossRef]

24. Keeney, J.; Boyd, E.M.; Sinha, R.; Westring, A.F.; Ryan, A.M. From "work-family" to "work-life": Broadening our conceptualization and measurement. J. Vocat. Behav. 2013, 82, 221-237. [CrossRef]

25. Thasni, A. Impact of work-life enrichment on organisational commitment and stress experiences: Mediating role of work-life balance. Int. J. Acad. Dev. 2017, 2, 1015-1019.

26. Dex, S.; Smith, C.; Winter, S. Effects of Family-Friendly Policies on Business Performance; Research Papers in Management Studies, WP22; University of Cambridge: Cambridge, UK, 2001.

27. Yasbek, P. The Business Case for Firm-Level Work Life Balance Policies: A Review of the Literature; Labour Market Policy Group: Wellington, New Zealand, 2004.

28. Pavalko, E.K.; Henderson, K.A. Combining care work and paid work. Do workplace policies make a difference? Res. Aging 2006, 28, 359-374. [CrossRef]

29. Lysova, E.I.; Allan, B.A.; Dik, B.J.; Duffy, R.D.; Steger, M.F. Fostering meaningful work in organizations: A multi-level review and integration. J. Vocat. Behav. 2019, 110, 374-389. [CrossRef]

30. Giddens, A. Sociology; Polish Scientific Publishers PWN: Warsaw, Poland, 2004.

31. Crouter, A.C. Spillover from family to work: The neglected side of the work-family interface. Hum. Relat. 1984, 37, 425-441. [CrossRef]

32. Grzywacz, J.G. Work-family spillover and health during midlife: Is managing conflict everything? Am. J. Health Promot. 2000, 14, 236-243. [CrossRef] [PubMed]

33. Sieber, S.D. Toward a theory of role accumulation. Am. Sociol. Rev. 1974, 39, 567-578. [CrossRef]

34. Greenhaus, J.H.; Powell, G.N. When work and family are allies: A theory of work-family enrichment. Acad. Manag. Rev. 2006, 31, 72-92. [CrossRef]

35. Carlson, D.S.; Kacmar, K.M.; Wayne, J.H.; Grzywacz, J.G. Measuring the positive side of the work-family interface: Development and validation of a work-family enrichment scale. J. Vocat. Behav. 2006, 68, 131-164. [CrossRef]

36. Russo, M.; Shteigman, A.; Carmeli, A. Workplace and family support and work-life balance: Implications for individual psychological availability. J. Posit. Psychol. 2016, 11, 173-188. [CrossRef]

37. Stoddard, M.; Madsen, S.R. Toward an understanding of the link between work-family enrichment and individual health. JBAM 2007, 9, 2-15. [CrossRef]

38. Staines, G.L. Spillover versus compensation: A review of the literature on the relationship between work and nonwork. Hum. Relat. 1980, 33, 111-129. [CrossRef]

39. Kelly, C.M.; Strauss, K.; Greenhaus, J.H.; Powell, G.N. Enrichment across boundaries: New perspectives on the work-life interface. Acad. Manag. Annu. Meet. Proc. 2015, 1, 14225. [CrossRef]

40. Rubenstein, A.L.; Peltokorpi, V.; Allen, D.G. Work-home and home-work conflict and voluntary turnover: A conservation of resources explanation for contrasting moderation effects of on- and off-the-job embeddedness. J. Vocat. Behav. 2020, 119, 103413. [CrossRef]

41. Powell, G.N.; Greenhaus, J.H.; Allen, T.D.; Johnson, R.E. Introduction to special topic forum: Advancing and expanding work-life theory from multiple perspectives. Acad. Manag. Rev. 2019, 44, 54-71. [CrossRef]

42. Henion, A.; Ryan, A.M. Wanted: A Life outside the Workplace. Available online: http://msutoday.msu.edu/news/2013/wanteda-life-outside-the-workplace/ (accessed on 15 November 2020).

43. Wayne, J.; Matthews, R.A.; Odle-Dusseau, H.; Casper, W.J. Fit of role involvement with values: Theoretical, conceptual, and psychometric development of work and family authenticity. J. Vocat. Behav. 2019, 115, 103317. [CrossRef]

44. McNall, L.A.; Nicklin, J.M.; Masuda, A.D. A meta-analytic review of the consequences associated with work-family enrichment. J. Bus. Psychol. 2010, 25, 381-396. [CrossRef]

45. Clutterbuck, D. The HR guide to organisational change: Managing work-life balance. NHRD Netw. J. 2009, 2, 109. [CrossRef]

46. Kvale, S. InterViews: An Introduction to Qualitative Research Interviewing; Sage Publications: Thousand Oaks, CA, USA, 1996 ; p. 88.

47. Lofland, J.; Lofland, L.H. Analyzing Social Settings: A Guide to Qualitative Observation and Analysis, 3rd ed.; Wadsworth: Belmont, CA, USA, 1995; p. 188. 
48. Strauss, A.; Corbin, J. Basics of Qualitative Research: Grounded Theory Procedures and Techniques, 4th ed.; Sage Publications: Newbury Park, CA, USA, 1990; p. 62.

49. Rosso, B.D.; Dekas, K.H.; Wrzesniewski, A. On the meaning of work: A theoretical integration and review. Res. Organ. Behav. 2010, 30, 91-127. [CrossRef]

50. Bowins, B. Activity for Mental Health; Academic Press: Cambridge, MA, USA, 2020; pp. 120-224.

51. Cropanzano, R.; Wright, T. When a "happy" worker is really a "productive" worker: A review and further refinement of the happy-productive worker thesis. Consult. Psychol. J. 2001, 53, 182-199. [CrossRef]

52. Oswald, A.J.; Proto, E.; Sgroi, D. Happiness and productivity. J. Labor Econ. 2015, 33, 789-822. [CrossRef]

53. Mishra, P.; Bhatnagar, J.; Gupta, R.; MacDermid-Wadsworth, S. How work-family enrichment influence innovative work behavior: Role of psychological capital and supervisory support. J. Manag. Organ. 2019, 25, 58-80. [CrossRef]

54. DiNardi, G. Why You Should Work Less and Spend More Time on Hobbies. Harv. Bus. Rev. 2019. Available online: https: / /hbr.org/2019/02/why-you-should-work-less-and-spend-more-time-on-hobbies (accessed on 19 November 2020). 